DOI 10.37882/2223-2982.2020.07.31

\title{
О ПОВЫШЕНИИ ЭФФЕКТИВНОСТИ ОБУЧЕНИЯ СТУДЕНТОВ НЕЯЗЫКОВЫХ ВУЗОВ ИНОЯЗЫЧНОЙ ПИСЬМЕННОЙ РЕЧИ С ИСПОЛЬЗОВАНИЕМ ДИСТАНЦИОННЫХ ОБРАЗОВАТЕЛЬНЫХ ТЕХНОЛОГИЙ
}

\section{ON IMPROVING THE EFFECTIVENESS OF TEACHING OF FOREIGN LANGUAGE WRITING USING DISTANCE LEARNING TECHNOLOGIES}

T. Usmanova

Summary: The purpose of this work is to find ways to solve technical, linguistic and other aspects of the task of implementing the distance learning of foreign written language of the non-linguistic universities' students. The task of compensating for the lack of direct "teacher-student" contact is formulated, leading to a noticeable decrease in language literacy and student competency compared to the traditional teaching. The scientific novelty of the paper consists in the systematization and classification of all problematic issues that arise in the educational process in the considered case. As a result, it was shown that for nonlinguistic universities, in order to create effective methods of teaching foreign written language in a e-learning form, it is necessary to improve both the didactic and technical aspects of the educational process, as well as the basis of digital educational resources.

Keywords: foreign writing; teaching written communication; distance learning; e-learning.

\section{Введение}

$\mathrm{C}$ тудент нелингвистического вуза обучается иностранному языку с целью развития умения осуществлять эффективную коммуникацию в профессиональной сфере, состоящую из устного и письменного аспектов. В рамках письменной части такой коммуникации, как правило, используются переписка (в том числе, электронная), составление, обработка и оформление документации, обмен информацией, оформление договорных отношений, сбор данных, изучение мнения различных групп и слоев общества и т.д. При этом будущий специалист должен уметь соблюдать речевой этикет и требуемую степень официальности речи, выбирать необходимые языковые средства, использовать социокультурные стереотипы речевого поведения носителей иностранного языка.

Вместе с тем в случае неязыковых вузов чаще всего не обеспечивается достаточный объем аудиторного вре-

\author{
Усманова Тургунай Алижановна \\ Преподаватель, Финансовый университет при \\ Правительстве РФ (2. Москва) \\ turgunai1@mail.ru
}

Аннотация: Целью работы является повышение эффективности процесса обучения студентов неязыковых вузов иноязычной письменной речи в дистанционной форме. Научная новизна исследования состоит в комплексном подходе к проблемам, связанным с дистанционным обучением письменной коммуникации на иностранном языке. Такое исследование позволяется классифицировать и систематизировать лингвистические, методические, технические и другие проблемные вопросы, характерные для образовательного процесса, реализованного в дистанционном режиме. В результате показано, что для неязыковых вузов создание эффективных методов обучения иноязычной письменной речи с использованием дистанционных образовательных технологий требует совершенствования как дидактической, так и технической сторон учебного процесса, а также создания единой базы электронных образовательных ресурсов.

Ключевые слова: иноязычная коммуникация; иноязычная письменная речь; дистанционное обучение; дистанционные образовательные технологии; электронные образовательные ресурсы. мени на обучение иностранным языкам из-за насыщенной образовательной программы, что компенсируется организацией самостоятельной работы студентов. С развитием информационно-коммуникационных технологий одним из эффективных инструментов организации самостоятельной работы обучающихся стали средства дистанционного обучения. Кроме того, глобальные события эпидемиологического характера в первой половине 2020 года, приведшие к полному запрету аудиторных занятий, продемонстрировали безальтернативность дистанционных образовательных технологий в таких случаях.

Специфика дистанционного обучения иноязычному письму заключается в создании условий для самостоятельного развития студентами умения эффективно коммуницировать на иностранном языке при содействии преподавателя [16]. При этом для указанной формы организации учебного процесса могут быть характерны свои сложности и недостатки, оказывающие отри- 
цательное влияние на качество овладения студентами необходимыми знаниями. Анализ научно-методической литературы свидетельствует о недостаточной проработанности вопросов выявления и устранения таких негативных факторов, что обуславливает актуальность настоящего исследования.

Отсюда можно сформулировать следующие задачи исследования:

- определить объект и предмет исследования;

- выявить негативные факторы, характерные для процесса обучения студентов неязыковых вузов иноязычной письменной речи с использованием дистанционных образовательных технологий;

- классифицировать и систематизировать выявленные негативные факторы;

- предложить способы устранения или уменьшения негативного влияния выявленных факторов с целью повышения эффективности образовательного процесса.

Для решения поставленных задач использованы такие методы научно-педагогического исследования, как поиск, обработка и систематизация научной информации; структурный анализ предметной области; обобщение.

В рамках настоящей работы объектом исследования является учебный процесс в целом. Предметом исследования выступает развитие у студентов неязыковых вузов умения иноязычной письменной коммуникации в режиме дистанционного обучения.

Теоретическую базу работы составляют концепция компетентностного подхода, лежащего в основе федеральных государственных образовательных стандартов высшего образования (ФГОС ВО), а также основополагающие принципы теории дистанционного обучения, изложенные в трудах Е.С. Полат [10] и других авторов. Также были использованы материалы указанных далее научно-методических и педагогических исследований.

Практическую значимость работы составляют полученные результаты, которые могут быть использованы при организации дистанционного обучения студентов нелингвистических вузов иноязычной письменной речи.

\section{Основная часть}

Далее рассмотрим основные факторы, негативно влияющие на эффективность процесса дистанционного обучения студентов иностранной письменной речи.

1) Информационно-технические факторы.

Дистанционное обучение подразумевает взаимо- действие преподавателя и студента на расстоянии с помощью какой-либо технологии передачи информации, в роли которой в подавляющем большинстве случаев сегодня выступает сеть Интернет. При этом указанное взаимодействие может включать в себя такие ресурсоемкие процессы как проведение видеоконференций, передачу потоковых аудио и видеоматериалов. Поэтому низкая пропускная способность Интернет-подключения взаимодействующих субъектов становится одним из факторов, негативно влияющих на качество учебного процесса.

Недостаточный уровень информационной и компьютерной грамотности студентов в настоящее время также стало препятствием для организации эффективного образовательного процесса [14], в том числе для дистанционного обучения иноязычной письменной речи. В частности, затраты времени на поиск, отбор, и переработку данных или на создание новых текстов на основе различных источников при отсутствии необходимых навыков информационно-поисковой деятельности и ясного осознания необходимости оценки собранной информации приводит к сокращению времени работы непосредственно над навыками иноязычной коммуникации. В результате не в должной мере могут быть развиты умения содержательно и выразительно изложить в письменной форме собственные мысли о событии, явлении, лице или предмете [15].

2) Лингвистические факторы.

При освоении студентами умения ведения электронной переписки могут наблюдаться ошибки, проявляющиеся в нарушении норм делового этикета:

- использование излишне эмоционально окрашенной лексики, сленговых выражений и неофициальной стилистики;

- применение необоснованного большого количества номенклатурных понятий, аббревиатур, специальных и профессиональных терминов;

- составление слишком длинных или слишком короткие фраз и текстов, не вызывающих интереса и отклика у респондента;

- нарушение структуры и требований к оформлению деловых писем;

- искажение смысла письма в результате нарушения лексических, синтаксических и орфографических правил иностранного языка, а также некорректного употребления иноязычных метафор и фразеологизмов.

Кроме того, в случае письменного общения с использованием мессенджеров или сервисов мгновенного обмена сообщениями могут наблюдаться ошибки в словообразовании, нарушение норм согласования и управления, некорректное построение 
фраз; искажение смысла и логики высказывания; неполное или неясное формулирование своей мысли; несоблюдение правил литературного языка [5].

В процессе работы над совместными проектами и документами с помощью соответствующих электронных сервисов и текстовых редакторов педагогические работники фиксируют у обучающихся:

- нарушения в вычленении абзацев, порядке предложений, применении предлогов и союзов для связи слов в предложениях;

- лексические повторы в предложениях для связи слов;

- незнание основных характеристик различных стилей текстов (описание, повествование, объяснение, полемика), а также фонетики, лексики, грамматики изучаемого языка;

- нехватку речевых и языковых средств;

- непонимание речевой задачи;

- неумение сокращать тексты большого объема, корректно обобщать данные разных источников, выделять в содержании важные моменты [17].

Для письменной дискуссии посредством блогов и социальных сетей характерным считается неумение выдвигать убедительные аргументы и контраргументы; формулировать собственное мнение; применять нестандартное, творческое мышление.

Значительную проблему представляет межъязыковая интерференция письменной речи, которая может встречаться даже у студентов, овладевших иностранным языком на сравнительно высоком уровне. Речь идет о передаче информации на изучаемом языке, основываясь на правилах грамматики и лексики родного языка, что может быть вызвано механическим заучиванием списков слов и недостаточным погружением в иноязычную языковую среду [2].

\section{3) Социокультурные факторы.}

Возможные недостаточные социокультурные компетенции также влияют на качество иноязычной письменной речи студентов. Из-за недостаточного знания страноведческой специфики, культуры, истории и современных реалий стран изучаемого языка могут наблюдаться фактологические неточности, применение неуместных языковых средств, нарушение правил речевого поведения, принятые в указанных странах. В результате возникает непонимание между участниками межкультурного общения, которые используют в письме одни и те же языковые структуры, на основанные на разных социокультурных явлениях [18].

4) Психологические факторы.
У большинства студентов не сформирована на должном уровне мотивационная составляющая для соблюдения требуемого темпа дистанционной самостоятельной работы в ситуации отсутствия внешнего контроля, что может быть вызвано следующими причинами:

- недостаточной осознанностью потребности овладения иноязычной речью в письменной форме;

- трудностью освоения данного речевого аспекта, вызываемой соблюдением по сравнению с устными высказываниями более сложных языковых критериев, использованием широкого спектра лексического запаса, необходимостью тщательной проработки грамматических конструкций, высокими требованиями к стилистике письменной речи, применением всего комплекса иноязычных знаний и умений, усвоенных в процессе обучения;

- отсутствием творческой направленности письменных упражнений, основанных на механическом запоминании материала;

- оторванностью содержания учебных материалов от реалий жизни и интересов обучающихся [7].

Существенную роль в снижении эффективности развития письменного аспекта иноязычной речи в условиях дистанционного обучения играет наличие у студентов коммуникативного, психологического, физического и языкового барьеров. Более того, можно утверждать, что дистанционное форма обучения не способствует развитию коммуникабельности, что связано с минимизацией или полным отсутствием непосредственных контактов студентов с преподавателем [5].

В дистанционных отношениях «преподаватель - студент» возможны также личностные барьеры, отражающие индивидуальные характеристики обучающегося и негативно влияющие на качество письменной речи. $\mathrm{K}$ такого рода характеристикам можно отнести разницу во взглядах на тот или иной вопрос, несовпадающие ценностные ориентации [21], а также принадлежность субъектов учебного процесса к разным языковым субкультурам и использование разной жаргонной, сленговой, профессиональной лексики [11].

Практика показывает, что в иноязычной письменной речи, которая развивается посредством электронных средств, может преобладать сиюминутность, невыразительность, краткость, необоснованная сжатость или излишнее применение речевых штампов. Прослеживается снижение уровня грамотности, связанное с применением программного обеспечения со встроенными функциями автоматической коррекции грамматики, орфографии и стилистики текста. Это приводит к размытию индивидуального стиля автора текста и к затруднениям с перефразированием мысли, требующим подбора оригинальных словосочетаний и выражений [23]. 


\section{5) Методические факторы.}

Анализ специализированной литературы свидетельствует о недостаточной проработанности вопросов создания методик повышения мотивационного аспекта иноязычной письменноречевой деятельности студентов неязыковых вузов, что в значительной степени препятствует развитию навыков грамотного письма у обучающихся. Также констатируется дефицит эффективных методик разработки виртуальной языковой среды, позволяющей обеспечить всестороннее учебное взаимодействие преподавателя и студента при совершенствовании навыков письменной речи. Не сформированы в полной мере комплексы электронных прикладных средств, способствующих качественному процессу обучения иноязычной письменной речи в дистанционном формате [6].

Экстренный и вынужденный переход на дистанционный режим обучения по всей стране в первой половине 2020 года, с одной стороны, можно рассматривать в качестве беспрецедентного по своим масштабам педагогического эксперимента, который позволил собрать уникальные по полноте, объемам и достоверности данные, требующие тщательного и всестороннего изучения в дальнейшем. С другой стороны, была наглядно продемонстрирована методическая неготовность образовательной системы к внедрению дистанционного формата, способного полноценно заменить традиционное обучение. В частности, получили подтверждение отмечавшиеся ранее специалистами проблемы текущего контроля и корректировки письменных работ студентов, которые преподаватель зачастую испытывает в условиях дистанционного обучения. При этом существенно снижается эффективность использования такой формы контроля, как тестирование [9]. В настоящее время не в полной мере разработаны детальные стратегии самостоятельной учебной деятельности студентов в рамках овладения иноязычной коммуникацией, в которые входило бы описание приемов и методов автономной деятельности студентов, письменного интерактивного взаимодействия с преподавателем, совместного овладения материалом с другими студентами, проведения контрольных и тестовых мероприятий в режиме реального времени. В целом, можно констатировать отсутствие единой и законченной ресурсной основы дистанционного курса обучения иноязычному письму, содержащей учебные и справочные материалы, средства контроля, а также методические указания по подаче и освоению учебного материала $[8,13]$.

Таким образом, основные факторы, способные оказывать негативное влияние на эффективность обучения иноязычной письменной речи в дистанционной форме, можно условно разделить на информационно-технические, лингвистические, социокультурные, психологи- ческие и методические. Далее рассмотрим возможные пути устранения или снижения воздействия указанных факторов.

1) Повышение информационно-технической грамотности обучающихся.

Для успешного прохождения обучения и последующей профессиональной деятельности студент должен выработать ряд необходимых компетенций. В частности, развитие навыка иноязычной письменной речи предполагает наличие информационной компетенции, для совершенствования которой со студентами начальных курсов рекомендуется выполнение информационноаналитической работы над иноязычным текстом: ответы на вопросы, сокращение и расширение текста, составление плана. Со студентами средних курсов можно практиковать информационный обмен не только с преподавателем, но и друг с другом, что позволит собирать и совместно перерабатывать данные, определять их важность для решения речемыслительных задач, устанавливать закономерности, причинно-следственные связи и делать выводы [1].

В рамках обмена информацией можно давать следующие задания:

- дополнить (сравнить, обсудить, расположить в порядке значимости) данные, полученные от коммуниканта;

- поддержать или опровергнуть мнение коммуниканта на основе полученной от него информации;

- проанализировать и описать предложенную преподавателем или сокурсником схему, составленную по тексту на заданную тему [20].

Для обучения студентов анализу иноязычной информации рекомендуется использовать такие задания, как подготовка письменного высказывания на основе разных источников информации; выбор в содержании главного и второстепенного моментов, сравнение с результатами сокурсника, обоснование своего выбора; составление для коммуниканта списка проблемных вопросов по анализируемой информации.

Для выработки умения нахождения необходимой информации, критической оценки и создания собственных текстов литературного, прикладного и информационного характера, можно предлагать выполнение следующих заданий в дистанционной форме:

- найти в заданном содержании информацию по списку критериев;

- определить связи между информационными отрывками;

- понять и интерпретировать сложный текст, выявить в нем ключевые сведения, проанализировать их, сформулировать выводы и гипотезы; 
- выделить в тексте трудные для восприятия моменты;

- выбрать из списка утверждения, соответствующие смыслу написанного;

- сделать краткий анализ статьи из журнала или отрывка из книги по специальности;

- выделить в тексте слова, несущие ключевую информацию [22].

Результатом систематической работы по развитию информационной компетенции студентов должны стать сформированные умения воспринимать и понимать иноязычную информацию, полученную от другого человека в письменном виде; фиксировать факты и формулировать личное отношение; определять основные положения, ключевые и второстепенные аспекты рассматриваемого вопроса [3].

К области информационной компетенции также относится владение навыками работы с прикладными программными продуктами и сервисами. В частности, для качественного овладения иноязычной письменной речью в режиме дистанционного обучения студенту потребуется умение пользоваться текстовыми редакторами, программами подготовки презентаций, а также программами и сервисами обучающего и проверяющего характера [19].

2) Решение лингвистического аспекта проблемы дистанционного обучения студентов иностранному языку.

Для обеспечения качественной работы студентов в рамках электронной переписки следует практиковать соблюдение делового речевого этикета в письме, а именно:

- использовать деловую лексику, общеупотребительные слова, вопросительные предложения вместо повелительных;

- пользоваться специфичными терминами только при условии, что они понятны респонденту, не допускать искажения терминов;

- сохранять достоверность (использование только проверенных фактов) и информативность (соблюдение заявленной темы);

- строить краткие, содержательные, культурные фразы;

- соблюдать правила и литературные нормы, логику и последовательность изложения;

- не навязывать собственное мнение;

- учитывать возраст и социальный статус собеседника.

Для обучения студентов коммуникации в системе мгновенного обмена сообщениями (мессенджерами), необходимо формировать умения «электронного диалога», при котором допускаются:
- отказ от социокультурных и психологических ограничений, направленных при реальном общении на неконфликтный разговор;

- разговорная или стилистически сниженная речь;

- использование лексических единиц нелитературного характера;

- неклишированность, отказ от шаблонных фраз, речевых штампов;

- использование принятых в странах изучаемого языка формул вежливости в усеченном или графически измененном виде; междометий и неологизмов, используемых для вхождения в разговор; форм благодарности, возникших в результате сокращения слогов, перемешивания букв и цифр; стандартных форм выхода из общения в мессенджере;

- экономия речевых усилий (не называть партнера по переписке по имени, обращаться к нему на «ты» с учетом возрастной и статусной равноправности или неопределенности собеседников; выражать личное отношение к написанному посредством смайлов; не пользоваться написанием слов заглавными буквами, если нет необходимости эмоционального выделения содержания).

В процессе улучшения навыков иноязычного общения студентов при работе над совместными проектами и документами следует обратить особое внимание на высокую динамику речевых контактов, а также такие их специфические особенности, как связанная с анонимностью свобода общения, невозможность глубокомысленных бесед и наличие обязательств участника по удовлетворению коммуникативных запросов партнера.

Также обучающиеся должны знать о других особенностях письменной коммуникации в совместных сервиcax:

- возможности скрывать чувства или выражать не те эмоции, которые на данный момент испытывает участник, что сказывается на снятии многих барьеров общения и продолжения диалога;

- допускается частая смена темы участниками;

- возможно применение усеченной формулы диалогических фраз;

- основными типами речевого взаимодействия являются отношения в форматах «вопрос - ответ», «побуждение - согласие/отказ». В ряде случаев могут использоваться форматы «просьба - согласие», «напоминание - благодарность».

Студентам следует знать, что в процессе общения в рамках совместных сервисов иногда может возникать недопонимание между участниками, связанное с невозможностью правильно оценить эмоциональное состояние или настроение коммуниканта. Общение часто строится в форме речевой игры, когда на передний план 
выступает не содержание написанного, а оригинальность ответной реакции. Практика показывает, что многим участникам виртуальной беседы требуется не серьезное содержание беседы, а сочувствие, поддержка, утешение или сопереживание.

В процессе работы над текстами с использованием текстовых редакторов студенты должны научиться выделять части текста, вычленять абзацы, соблюдать порядок предложений и связывать в них слова посредством предлогов и союзов. Например, для формирования навыка ведения языкового электронного портфолио следует уметь правильно хранить на необходимую для этого информацию: образцы документов, подтверждающих достижения студента в области изучения иностранного языка (сертификаты, дипломы), свои личные и групповые проекты, разного рода оценочные листы и отзывы. Портфолио должно быть удобно для профессиональной оценки деятельности обучающегося преподавателем, то есть иметь логичную структуру с отражением результатов различных видов речевой деятельности. Такую структуру можно в дальнейшем применить для создания веб-версии электронного портфолио, которое в условиях дистанционного обучения представляется более удобным тем, что к нему могут иметь доступ в любой момент времени не только сам студент, но и его языковые партнеры, а также преподаватель. Это расширяет возможности иноязычных речевых контактов и способствует развитию навыков письма на изучаемом языке.

Студентам с высоким уровнем мотивации овладения иностранным языком в целях совершенствования навыков письма, а также самостоятельной исследовательской работы, можно рекомендовать наряду с электронным портфолио также оформление:

- языкового паспорта (самооценка сформированности умений и навыков);

- языковой автобиографии (описание процесса овладения иностранным языком в вузе);

- языкового досье (примеры применения на практике усвоенных знаний и сформированных умений и навыков);

- сборника рабочих материалов, демонстрирующих самостоятельную деятельность по овладению языком.

В ходе организации работы студентов над текстами с помощью электронных сервисов генерации следует акцентировать внимание на развитии письменноречевых навыков за счет подробного изучения характеристик различных стилей текстов, правил грамматики, лексики, фонетики, структурирования и логичного изложения содержания; учить грамотно и критически обобщать информацию, полученную из различных источников, сокращать большие тексты профессионального содержания, соблюдать правила и нормы написания разверну- тых текстов; выделять ключевые моменты содержания, аргументированно доказывать свою точку зрения; соблюдать правила работы с двуязычными словарями при оформлении терминологических списков.

Необходимо также довести до сведения обучающихся специфику работы с такими сервисами. Обучающийся, организуя учебный труд в соответствии со своими индивидуальными особенностями, должен иметь возможность сотрудничать с других сокурсником, как в плане создания материала, так и его критического анализа. При этом в процессе обсуждение критериев оценки выполненной работы, основное внимание участникам следует обратить на языковой аспект.

Организации эффективной речевой деятельности с использованием блогов и социальных сетей способствует совершенствование умений выдвигать в процессе письменной дискуссии убедительные аргументы и контраргументы, четко формулировать собственное мнение, оперативно находить требуемую информацию с помощью архивов и рубрикаций, стремиться к нестандартным способам мышления, творческой и креативной оценке информации.

Важную роль играет также знание особенностей блог-технологий: хронологический порядок размещения сообщений; осуществление модерации блога только его автором; отсутствие возможности внести изменения в опубликованный материал участниками дискуссии, за исключением автора блога. Кроме того, мультимедийный характер блогов способствует обогащению лексического и социокультурного аспекта содержания при написании текстов. Данная технология хорошо подходит для самостоятельного написания и последующего обсуждения эссе. В сетевом пространстве можно не только размещать свои работы, но и размышлять, и получать советы других участников, а также рекомендации преподавателя.

Для развития у обучающихся умений подготовки презентаций необходимо практиковать логичное структурирование текста; составление тезисов; соблюдение правил написания слов, оформления прямой и косвенной речи; исключение ошибок, связанных с влиянием друг на друга родного и изучаемого языков; соблюдение управления и видовременных отношений глаголов; сохранение стиля речи, смысловой законченности текста. При этом полезным представляется выполнение следующих заданий:

- составить план содержания, правильно сформулировать тему презентации и ее основную идею;

- охарактеризовать структуру;

- составить информативное введение;

- выделить подтемы, к каждой из них составить первое предложение, раскрывающее суть, подо- 
брать интересные и содержательные идеи;

- в заключении обобщить материал и ответить на ключевой вопрос презентации, не повторяя текст основной части (можно использовать перефразирование).

В процессе наполнения презентации при выборе языковых средств следует придерживать следующих рекомендаций:

- составлять короткие, адаптированные к устной речи, предложения;

- вместо пассивного залога использовать в конструкциях активный; минимизировать использование незнакомых слов;

- использовать не буквальный перевод, делающий письменную речь неживой, а аутентичный текст, содержащий готовые конструкции изучаемого языка;

- после написания проговорить текст, проверив соблюдение грамматических норм и правил, длину, логику и связность частей предложений, обоснованность перехода от одной части к другой, убедительность и достоверность фактов и деталей, подтверждающих ключевые высказывания;

- не размещать на слайдах образцы письменной речи, не воспринимаемые на слух: цитаты, ссылки, громоздкие определения;

- для выразительности текста пользоваться речевыми клише;

- обязательно указывать все источники информации [4].

При дистанционном обучении студентов иноязычному письму следует уделять наиболее пристальное внимание области паронимии и омонимии, которая в результате лингвистических исследований была признана одной ключевых причин потенциальной языковой интерференции. Для этого рекомендуется регулярно показывать на примерах многозначность паронимов, результаты нарушений границ лексической сочетаемости, употребления паронимов без учета стилистической окраски или понимания иноязычной сущности последних, некорректность формулировок, вызванную смешением паронимов.

Для профилактики омонимии целесообразно подготовить для ознакомления студентов список представляющих трудности лексических единиц, имеющих интерферирующее значение и отработать такие словообразования на практических примерах. Можно выделить группы слов, значения которых совпадают в родном и изучаемом языке полностью, частично и не совпадают совсем.

В целом, несмотря на очевидную тенденцию формирования особой, цифровой, культуры речи, необходимо постоянно напоминать обучающимся о том, что образованный человек должен писать на правильном литературном иностранном языке с соблюдением всех норм и требований.

\section{3) Совершенствование социокультурного компонента}

Удовлетворительное владение студентами умениями и навыками иноязычной письменной коммуникации требует систематической работы над социокультурным компонентом речевой деятельности. Для выработки привычки осознанного и адекватного применения в иноязычном общении знаний о культурных особенностях, коммуникативном поведении, традициях и этикете носителей языка преподавателю необходимо на регулярной основе знакомить обучающихся с самыми разнообразными сферами жизни общества в соответствующих странах. В этом случае иноязычная социокультурная компетенция формируется на основе знаний о национальных особенностях быта, традиций обычаев народа, семантики социально-речевых ситуаций, специфики речевого этикета и невербального социального поведения. При качественно развитых и активно взаимодействующих страноведческом, лингвострановедческом и социокультурном компонентах иноязычная письменная речь становится эффективным средством межкультурного общения.

В рамках дистанционного курса следует применять аутентичные электронные материалы, создавать условия для формального и неформального общения на иностранном языке, создавать ситуации, показывающие межкультурные проблемы, возникающие при нарушении языковых прав и свобод личности, приучать студентов правильно обрабатывать и адекватно использовать в межъязыковом общении информацию социокультурного характера.

\section{4) Преодоление психологических барьеров}

Такие психологические барьеры, как страх иноязычного контакта с другим человеком, взаимного непонимания, говорения на чужом языке, совершения ошибок в межкультурном пространстве снимаются за счет выбора преподавателем для студента индивидуальных техник и приемов коммуникаций, организации регулярных тренировок в письменном выражении на иностранном языке собственных идей и мыслей, систематического изучения культуры разных стран, расширения кругозора, воспитания толерантности. В этом плане дистанционный формат может выступить промежуточным или подготовительным этапом на пути к традиционной речевой коммуникации.

Причинами семантических барьеров являются бессвязность речи или использование сленговых лексиче- 
ских единиц изучаемого иностранного языка. Для устранения таких препятствий следует приучать студентов к правильному подбору слов для высказываний, согласованию предложения и фразы, избеганию повторов и тавтологий, исключению нелитературных выражений и жаргонизмов.

Для преодоления языкового барьера преподавателю рекомендуется работать над уменьшением пассивности обучающихся и нежелания выполнять письменные задания, в которых задействована речь, а также поощрять развитие студентами умения осмысленно описывать факт, событие, явление или объект. Для этого важно стимулировать развитие воображения и приобретению социального опыта студентами.

В ходе выбора средств мотивации обучающихся к самостоятельной письменной работе на иностранном языке преподавателю необходимо убедиться, что использование той или иной технологии оправдано и будет способствовать достижению конкретной цели, а именно:

- применять потоковые аутентичные видеоматериалы и современную музыку, возможности инструментов телеконференций и социальных сетей;

- создавать с учетом сильных и слабых сторон обучающихся индивидуальные интерактивные упражнения, цифровые генераторы игр и дидактического материала;

- производить самостоятельно или вместе со студентами уникальные подкасты;

- вести блоги и электронные дневники;

- по возможности выбирать актуальные предметные темы, которые вызовут интерес и яркие эмоции у обучающихся [12].

Помочь студенту в преодолении коммуникативного барьера при дистанционном овладении навыками письменной речи можно путем совместного выявления и разъяснения причин появления такого барьера, а также мотивации желания обучающегося избавиться от проблемы, обеспечив квалифицированной помощью и создав ситуации общения, близкие к реальным. Сделать это можно посредством учета личностных особенностей людей, создания благоприятного психологического климата, атмосферы доброжелательности и взаимной поддержки.

5) Методические факторы.

Как выше было показано, анализ литературы свидетельствует, о необходимости разработки, прежде всего, методик повышения мотивации к освоению иностранного языка в дистанционной форме студентами неязыковых вузов, что, в свою очередь, станет толчком к совершенствованию и навыков грамотного письма.
Кроме того, важную роль играет контроль выполнения заданий в интерактивном режиме, который можно осуществлять с помощью интегрированных средств в составе применяемых дистанционных систем обучения. Например, можно использовать так называемую систему открытых и закрытых вопросов. На открытые вопросы обучающийся самостоятельно вводит ответы в систему, которая доставляет их на проверку преподавателю и сохраняет результаты проверки. Ответы на закрытые вопросы, которые можно интегрировать в учебный материал, проверяются системой в автоматическом режиме, а полученные результаты могут быть использованы для оценки уровня сложности и готовности перехода к следующему заданию.

В целом тщательно продуманная и эффективная система дистанционного контроля иноязычной речевой деятельности студентов в письменной форме станет важным инструментом мотивации качественной и своевременной самостоятельной учебной деятельности обучающихся. Также в целях обеспечения плодотворного дистанционного взаимодействия преподавателя и студента при развитии и совершенствовании навыков письменной речи следует обратить пристальное внимание на методики создания целостной виртуальной языковой среды со всеми необходимыми средствами и материалами по аналогии с традиционным обучением.

\section{ЗакАючение}

В рамках повышения качества процесса овладения студентами иноязычной письменной речью необходимо уделить больше внимания разработке систем электронных, прикладных, инструментальных и коммуникационных средств обучения в вузах, а также созданию единой ресурсной основы [10].

Одним из путей преодоления названных проблем может быть увеличение количества учебных часов на дистанционное обучение иноязычному письму и выделение некоторой их части на ознакомление с классической литературой на изучаемом языке. Также важной представляется разработка единой стратегии обучения самостоятельной учебной деятельности при овладении иноязычным письмом студентами неязыковых вузов.

Преподавателям иностранных языков в неязыковых вузах для создания эффективных методов обучения иноязычной письменной речи в дистанционной форме рекомендуется совершенствовать как дидактическую, так и техническую стороны учебного процесса, а также базу электронных образовательных ресурсов. Следует систематически повышать свой профессиональный уровень не только в языковом плане, но и в части овладения современными цифровыми технологиями. 


\section{ЛИТЕРАТУРА}

1. Бороненко Т.А., Кайсина А.В., Федотова В.С. Диалог в дистанционном обучении // Высшее образование в России. 2017. №8-9. С. 131-134.

2. Буримская Д.В. Современное состояние обучения иностранному языку на базе информационных и коммуникационных технологий // Педагогика и психология образования. 2017. №1. С. 60-71.

3. Гайсина 0.С. Использование информационно-компьютерных технологий в подготовке студентов неязыковых вузов // Мир педагогики и психологии. 2018. №6 (23). С. 76-82.

4. Гайсина 0.С. Проектный метод обучения иностранным языкам в неязыковых вузах // Теория и практика обучения иностранным языкам в неязыковом вузе: традиции, инновации, перспективы. Сборник научных работ - М., 2016. С. 61-64.

5. Глазнева С.Е., Коняева Е.А. Положительные и отрицательные стороны дистанционного обучения // «Актуальные проблемы образования: позиция молодых»: материалы Всероссийской студенческой научно-практической конференции. Челябинск. 2016. С.57-59.

6. Загузина Н.Н., Невзоров Б.П. Проблемы развития дистанционной педагогики // Вестник Кемеровского государственного университета. 2014. №4-3 (60). C.64- 66.

7. Марчук Н.Ю. Психолого-педагогические особенности дистанционного обучения // Педагогическое образование в России. 2013. №4. С. 78-85.

8. Назаренко А.Л. К вопросу об информатизации лингвистического образования // Вестник Московского университета. Серия 19: Лингвистика и межкультурная коммуникация. 2010. №1. С. 114-121.

9. Перова Ю.П. Технологии тестирования в дистанционном обучении // Доклады ТУсУР. 2015. №1 (35). С. 138-141.

10. Полат Е.С. Теория и практика дистанционного обучения: Учеб. пособие для студ. высш. пед. учеб. заведений - М., Издательский центр «Академия», 2004. 416 c.

11. Полякова Л.0. Коммуникативно-языковые барьеры в иноязычном обучении студентов вузов как психолого-педагогическая проблема // Современные наукоемкие технологии. 2016. № 3-1. С.199-202.

12. Правдина 0.А., Рассказова А.А. Преимущества использования сетевых систем дистанционного обучения // Санкт-Петербургский образовательный вестник. 2018. №1-2 (17-18). С. 45-48.

13. Умнягина К.А. Проблема интеграции дистанционного обучения в систему заочного образования в языковом вузе // Вестник МГлу. Образование и педагогические науки. 2015. Вып. 4 (715). С. 107-117.

14. Хамицева С.Ф. Компьютерные технологии в обучении иностранным языкам // Молодой ученый. 2015. №8. С. 1057-1059.

15. Чигинцева А.А. Актуальные проблемы дистанционного обучения // Вопросы студенческой науки. 2018. №3 (19). С. 10-13.

16. Щуровская Е.В. Дидактические возможности использования Интернет-технологий в обучении студентов неязыкового вуза иноязычной письменной речи // Вестник МГЛУ. Сер. 2. Педагогика. Психология. Методика преподавания иностранных языков. 2007. №2(12). С. $35-42$.

17. Amano T., González-Varo J.P., Sutherland W.J. Languages Are Still a Major Barrier to Global Science // PLoS Biol, 2016, Vol. 14, No. 12: e2000933. doi:10.1371/ journal.pbio.2000933.

18. Chen-On Then, David and Ting, Su-Hie. Code-switching in English and science classrooms: more than translation // International Journal of Multilingualism Vol. 8, No. 4. 2011. pp. 299-323.

19. Deane F.P., Gourney K. Leading a multidisciplinary team. Chapter 1. Available from: https://www.researchgate.net/publication/242558033 (Дата обращения: 20.03.2020).

20. Lei L., Liu D. A new medical academic word list: A corpus-based study with enhanced methodology // Journal of English for Academic Purposes. 2016. Vol. 22. pp. 42-53.

21. McNaught K., Benson S. Increasing student performance by changing the assessment practices within an academic writing unit in an Enabling Program // The International Journal of the First Year in Higher Education. 2015. Vol. 6 (1). pp. 73-87.

22. Tate P., Klein-Collins R. PLA and CBE on the Competency Continuum. The Relationship between Prior Learning Assessment and Competency-Based Education. Council for Adult and Experimental Learning. 2015. www.cael.org (Дата обращения: 26.03.2020).

23. Yang A. et al. Epistemic modality in English-medium medical research articles: A systemic functional perspective // English for Specific Purposes. 2015, Vol.38. pp. 1-10.

(c) Усманова Тургунай Алижановна (turgunai1@mail.ru).

Журнал «Современная наука: актуальные проблемы теории и практики» 